\title{
Future differential vulnerability to natural disasters by level of education
}

\author{
Erich Striessnig and Elke Loichinger*
}

\begin{abstract}
The present paper looks at the implications of anticipated changes in population size and composition for the projected number of deaths from natural disasters Building on empirical evidence from cross-country time series of factors associated with natural disaster fatalities since 1970 in 174 countries, the paper first highlights the major role of education in enabling people to cope with weather extremes in the past. Using the five demographic scenarios implied by the Shared Socioeconomic Pathways (SSPs), which include trajectories for the future of educational expansion, this evidence is translated in the second part of the paper into projections of the number of deaths from climate-related extreme natural events for six major world regions. Assuming constant hazard, we demonstrate the importance of including in assessments of future vulnerability not only the projected population size but the full population heterogeneity by age, sex and level of education.
\end{abstract}

\section{Introduction}

Following a widespread definition, environmental risk can be described as a function of hazard and vulnerability (Brooks et al. 2005). Hazard is usually a necessary precondition for natural disasters, but it typically also requires a vulnerable population who are exposed to the hazard. While hazard is largely geographically determined, or is a matter of 'where' you are; vulnerability is strongly linked to social factors, or is a matter of 'who' you are. In searching for ways of reducing future risks associated with natural catastrophes, we thus need to look more closely at the determinants of vulnerability. Given that changing climatic conditions are

\footnotetext{
${ }^{*}$ Erich Striessnig (corresponding author), Wittgenstein Centre for Demography and Global Human Capital (IIASA, VID/ÖAW, WU), International Institute for Applied Systems Analysis (IIASA), Vienna Institute of Demography, Austrian Academy of Sciences, Vienna, Austria

Email: striess@iiasa.ac.at

Elke Loichinger, College of Population Studies, Chulalongkorn University, Bangkok, Thailand
} 
expected to lead to both more frequent and more catastrophic extreme weather events, levels of future vulnerability to natural disasters will be closely related to societies' adaptive capacities.

As an important source of premature mortality, vulnerability to natural disasters is of significant demographic interest, even in the absence of climate change. One important characteristic of vulnerability that has been studied extensively is age. Vulnerability to natural disasters affects people at all stages of their life course. While there is some evidence that people at the very beginning and at the very end of their life cycle are more vulnerable because they directly depend on the help of others, other factors tend to dominate differences in the risks faced by non-elderly adults (KC, Lutz, et al. 2014). These factors range from household characteristics associated with economic standing (such as the construction and stability of the house) to the ecological setting of the house, to individual behavioural variables.

Less attention has been paid in risk studies to the important role of another individual characteristic: namely, the level of educational attainment. This gap in the research has recently been filled in part by a series of studies published as a special issue of Ecology $\mathcal{E}$ Society, which clearly demonstrated the decisive role of education in risk reduction (Butz et al. 2014). But in general, the future adaptive capacities of societies and the differential vulnerabilities of their members continue to be among the least studied aspects of the important question of how dangerous climate change is likely to be for future human well-being.

To study more thoroughly the interactions of socioeconomic developments and societies' levels of resilience to climate change, and also to provide a scenario 'thread' through the different climate research communities (van Vuuren et al. 2012), the global integrated-assessment modelling community has recently joined forces with the impacts, adaptation, and vulnerability community to launch a new scenario development effort (Kriegler et al. 2012), which has resulted in the creation of a set of scenarios known as the Shared Socioeconomic Pathways (SSPs). The SSPs are representative narratives of how the world might develop over the course of the $21^{\text {st }}$ century that follow a widely negotiated and sufficiently broad range of possible alternative trajectories, particularly with regard to future societies' capacities for mitigation and adaptation to climate change (O'Neill et al. 2013). Using these narratives, researchers can integrate their findings and make them comparable across a range of different fields, thereby broadening the scope of our knowledge about the likely implications of climate change.

The original narratives underlying the SSPs have been translated into the language of demographic change by KC and Lutz (2014). By uncovering the 'human core of the SSPs', the authors have provided comprehensive assumptions regarding the future of fertility, mortality, migration, and education for all countries in the world. They emphasised that after age and sex, education is the third most important source of observable population heterogeneity, and thus demanded the default inclusion of education in population projections. In light of its strong influence on the determinants of population development, education is one of the key variables in the SSPs. As good quality data on years of schooling are hard to come 
by, education in the SSPs is measured by attainment; i.e. by the specified educational level. The six categories of educational attainment are no education, incomplete primary, completed primary, lower secondary, upper secondary, and post-secondary education. The methodological difficulties that had to be overcome in order to produce the most comprehensive dataset on global educational attainment to date are described in full detail in KC, Potančoková et al. (2014).

As has been pointed out by Hunter and O'Neill (2014), the SSPs can be used to project the effects of demographic trends into the future. Some examples of such translation attempts include the use of the SSPs for projecting future GDP per capita (Crespo Cuaresma 2015), assessing the urbanisation impacts from different scenarios (Jiang and O'Neill 2015), estimating the damage and adaptation costs resulting from future sea level rise (Hinkel et al. 2014), and estimating the likelihood of future armed conflict (Hegre et al. 2016).

In this paper, we attempt to provide a similar and innovative translation of the SSPs to address the issue of future vulnerability to extreme natural events for six world regions. We explicitly incorporate information from the SSPs about changes in countries' population sizes and educational structures. With strong support from the results presented in Ecology $\mathcal{F}$ Society (Muttarak and Lutz 2014), our central hypothesis is that education can play an important role in reducing the negative impacts of climate change on future disaster-related mortality. Building on updated empirical evidence from cross-country time series of factors associated with past natural disaster fatalities since 1970 in 174 countries (Striessnig et al. 2013), we first quantify the central role of education in reducing fatalities due to natural disasters. We also introduce the concept and the narratives of the SSPs, and show what the different development paths would mean for future total population sizes for each world region. In the second part, we translate the model results into projections of numbers of deaths due to climate-related extreme natural events, while making use of the five demographic scenarios as defined by the SSPs. The results are presented in the form of the predicted number of deaths for each major world region, ${ }^{1}$ and illustrate the effect education is expected to have on future fatalities through changes in the total size and the educational composition of each population.

\section{Data and model specification}

Our main source of data for studying the differential impact of natural catastrophes in different parts of the world is the Emergency Events Data Base (EM-DAT 2010) maintained by the Centre for the Research of the Epidemiology of Disasters. The EM-DAT provides information on different disaster outcome measures such as total financial damage and number of deaths, as well as an approximate estimate of the number of people affected by a wide range of different types of natural disasters

1 For a complete list of all countries by region, see Table A.1 in the appendix. 
since 1900. Of these three measures, we decided to use the number of deaths per million of population as our dependent variable, as it is more reliable and measurable than the other two.

It is important to note that deaths may be undercounted in the EM-DAT. In a recent comparison with WHO death registration data, Zagheni et al. (in this issue) showed that the EM-DAT figures appear to underrepresent deaths from small disasters that did not qualify as natural catastrophes under the EM-DAT criterion of having caused at least 10 casualties. $^{2}$ Yet in assessing the impact of natural disasters it is still preferable to use the number of deaths rather than financial damage figures. Because financial damage estimates are mainly driven by a country's wealth, they tend to overstate damage in rich nations, while making it difficult to determine the number of people affected. Moreover, because they are often made in the turbulent aftermath of natural disasters, estimates of financial damage tend to be vague and unreliable.

It is also important to point out that before the advent of modern communication technologies and mass media, the likelihood that disasters would be detected varied across the globe. We therefore restrict ourselves to the period 1970-2010, and aggregate our data by 10-year intervals to limit the influence of extreme outlier years and events. Since we are primarily interested in those events that can be expected to increase as a function of climate change, we further limit our analysis to six different types of hydro-meteorological disasters. ${ }^{3}$

On the explanatory side of the equation, we account for the disaster hazard by controlling for the number of disasters a country experienced within a given decade, again using data from the EM-DAT. Exposure is controlled for first by assessing the number of deaths on a per million population basis. In addition, we include the land mass of a country that is actually inhabited. The proxy used here is arable land as reported by the World Bank's development indicators (2012). Since our main hypothesis is that people are affected differently depending on a country's average level of educational attainment, we also control for the share of women aged 2039 with at least secondary education. Previous research that considered not just the total population, but the distribution of the population by age, sex, and level of educational attainment, has shown that this variable is highly relevant in studying topics as diverse as economic growth or the transition to a free democracy (Lutz et al. 2008; Lutz et al. 2010). According to these earlier findings, the share of women aged 20-39 with at least secondary education is the indicator that best reflects

\footnotetext{
2 The three remaining criteria used by the EM-DAT include (1) 100 or more people affected, (2) a declaration of a state of emergency, and (3) a call for international rescue help. If any one of these four criteria is met, an event is counted as a disaster in the EM-DAT database. As not all disasters meet these criteria, we can assume that the number of disasters is underestimated.

3 These are droughts, floods, storms, extreme temperature events, wildfires, and landslides. Note that our results are not sensitive to the exclusion of deaths from geophysical events and other less catastrophic types of disasters.
} 
Figure 1:

Frequency distribution of number of deaths due to natural disasters, 1970 to 2010

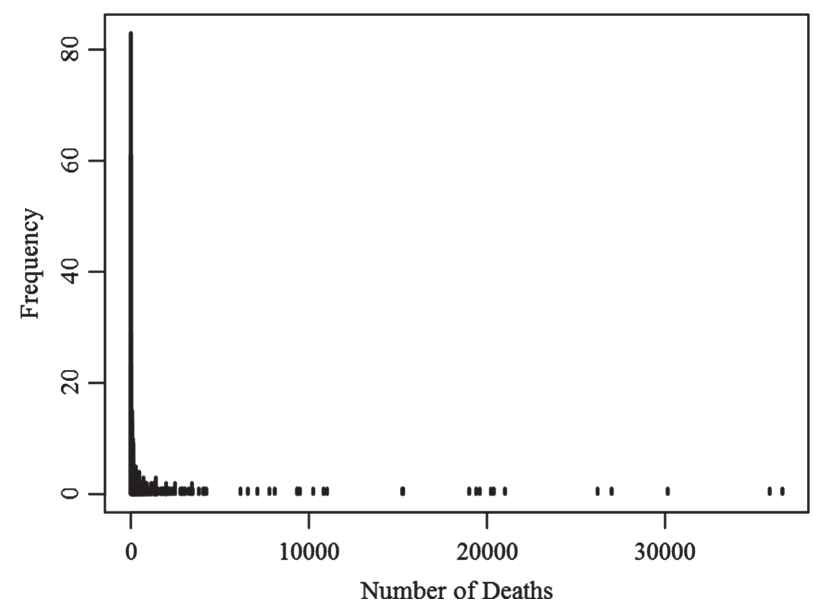

Source: EM-DAT.

inequality, and that has the greatest discriminatory power. Because women aged 2039 play central roles in family matters ranging from childbearing to family health to changes in the labour force participation of household members, they seem to be of particular importance for social as well as economic development. The data are obtained from the latest reconstruction of population by age, sex, and educational attainment by the Wittgenstein Centre for Demography and Global Human Capital in Vienna (Lutz et al. 2014). Additional controls include population growth rates and infant mortality rates from the United Nation's World Population Prospects (2013), as well as time-fixed effects and 26 world regions comprised of countries from the same geographical region with the same most frequent disaster type among the six disaster types included.

\subsection{Estimation method}

Figure 1 presents the distribution of the number of deaths due to natural disasters observed in the EM-DAT over the period 1970-2010, which is our outcome of interest. As can be seen in Figure 1, there are many country-year combinations in our sample that report zero casualties from natural catastrophes. ${ }^{4}$ At the same time, the variable we are trying to explain appears to be severely over-dispersed. In 83 out of

\footnotetext{
4 In these cases, an event was counted as a disaster in the EM-DAT database because one of the other three criteria - other than the criterion of having caused at least 10 deaths —is applied.
} 
554 observations, the proportion of zeroes is rather high compared to the distribution of the positive count outcomes; and while the majority of all disasters caused fewer than 1000 casualties, seven disasters in the observational period were responsible for more than 40,000 deaths each. To avoid distortions in our predictions due to the extreme magnitudes of these outliers, we exclude them from our analysis. ${ }^{5}$

This distribution of the number of deaths due to natural disasters suggests that the application of a zero-inflated negative binominal or a hurdle model would be appropriate, as both models can deal with the presence of excess zeroes and overdispersion (Atkins et al. 2013). The difference between the two models lies in the assumptions made about the origin of zeroes. In the hurdle model all zeroes are assumed to originate from the same process (sampling zeroes), whereas the zeroinflated models are built on the assumption that there are two kinds of zeroes: sampling zeroes and structural zeroes (Frome et al. 2012). Since there is no reason to assume that there are structural zeroes in our dependent variable-i.e. there is no reason to believe that in any country a natural disaster would not be able to cause any death per se-we apply a hurdle model. We estimate the model using the $\mathrm{pscl}$ package in $\mathrm{R}$ (Zeileis et al. 2007). Hurdle models are two-part models in which a model that explicitly models zero- vs. non-zero outcomes is combined with a model that only handles non-zero outcomes (Atkins et al. 2013). In our analysis, outcomes of non-zero disaster deaths are modelled as a negative binomial regression with a log link function (count model), whereas observations with zero deaths are dealt with in a binomial regression with a logit link function (zero model). This combination can be described more formally as

$$
f_{\text {hurdle }}(y ; x, z, \beta, \gamma)= \begin{cases}f_{\text {zero }}(0 ; z, \gamma) & \text { if } y=0 \\ \left(1-f_{\text {zero }}(0 ; z, \gamma)\right) * \frac{f_{\text {count }}(y ; x, \beta)}{1-f_{\text {count }}(0 ; x, \beta)} & \text { if } y>0\end{cases}
$$

where the model parameters $\beta$ and $\gamma$ are estimated by maximum-likelihood (Zeileis et al. 2007).

\subsection{Results from hurdle negative binomial regression models}

Earlier results by Striessnig et al. (2013) suggested that education, especially for women, plays a significant role in reducing disaster fatalities after controlling for other key determinants of socioeconomic development and exposure to risk. These results are confirmed when using a larger number of countries and the refined estimation strategy just described (Table 1). Our approach generates separate estimation results for observations in which a natural disaster led to at least one death (count model, prob $(\mathrm{Y}>0)$ ) or to no deaths (zero model, prob $(\mathrm{Y}=0)$ ).

5 The excluded disasters were in Bangladesh (1970), Ethiopia (1978 and 1984), Mozambique and Sudan (1985), Bangladesh (1991), and Myanmar (2008). 
Table 1:

Determinants of national deaths from natural disasters per million of population. Hurdle regression for 174 countries over 10-year intervals between 1970 and 2010

\begin{tabular}{|c|c|c|}
\hline Variables & $\operatorname{Prob}(Y>0)$ & $\operatorname{Prob}(\mathbf{Y}=0)$ \\
\hline Constant & $\begin{array}{c}-3.073^{* * *} \\
(0.72)\end{array}$ & $\begin{array}{c}11.735 \\
(8115.58)\end{array}$ \\
\hline Log (\#Disasters) & $\begin{array}{c}0.796^{* * *} \\
(0.13)\end{array}$ & $\begin{array}{c}4.027^{* * *} \\
(0.52)\end{array}$ \\
\hline Log (Arable Land in $\mathrm{km}^{2}$ ) & $\begin{array}{c}-1.083^{* * *} \\
(0.14)\end{array}$ & \\
\hline Logged IMR & $\begin{array}{c}0.331^{* *} \\
(0.14)\end{array}$ & \\
\hline Logit (Share Fem 20-39 Sec + Edu) & $\begin{array}{c}-0.451^{* * *} \\
(0.16)\end{array}$ & $\begin{array}{c}-0.889^{* *} \\
(0.37)\end{array}$ \\
\hline Pop Growth Rate & $\begin{array}{c}0.700^{* * *} \\
(0.09)\end{array}$ & \\
\hline Log (Theta) & $\begin{array}{c}-0.554^{* * *} \\
(0.07)\end{array}$ & \\
\hline Dummies for 26 World Regions & YES & YES \\
\hline Dummies for Decadal Periods & YES & YES \\
\hline $\begin{array}{l}\text { Log-likelihood } \\
\text { AIC } \\
\text { BIC } \\
\text { N }\end{array}$ & $\begin{array}{r}-3 \\
6 \\
6\end{array}$ & $\begin{array}{l}57 \\
49 \\
43 \\
54\end{array}$ \\
\hline
\end{tabular}

Note: Theta is the dispersion parameter. For a comparison of the model fit with two alternative model specifications using GDP per capita instead of education, see Table A.1 of the appendix. Significance codes: $0.01=^{* * *} ; 0.05=^{* *}$; $0.1=^{*}$.

We first ran the model using all of the explanatory variables in both models, and then ran it again while excluding the variables that were insignificant in the first run. As shown in Tables A.2 and A.3 in the appendix, including the insignificant variables has only minor effects on our results.

In the part of the model that explains the occurrence of 'zero' casualties, apart from the obviously important logged number of disasters, only the education variable turns out to have a significant effect pointing in the expected direction: whereas a greater number of disasters increases the likelihood that a country will experience one or more deaths, having a higher share of the population with secondary education decreases the probability that an event will clear the hurdle 
and have a positive casualty count. In the count part of the model we found that in addition to the variables already included in the zero model, a country's arable land mass, population growth rate, and lagged infant mortality rate are significant predictors of disaster impact. In line with the definition of risk given above, our results show that countries with vast, thinly populated areas used primarily for agricultural purposes experience lower deaths per million of population. Conversely, population pressure, as measured by the population growth rate, tends to put pressure on infrastructures that may not be capable of dealing with intensified environmental conditions. In addition, as rapid population growth often does not allow for adequate planning of settlement projects, countries with fast-growing populations may have large numbers of highly vulnerable informal settlements. Not surprisingly, the infant mortality rate, which can be seen as a proxy for the capacities of a country's health care system, can reveal weaknesses in national coping strategies. As has been shown by Pamuk et al. (2011), there is a strong case that investments in education can help countries reduce their infant mortality rates.

\subsection{The SSP scenario framework}

The SSPs were designed to include both a qualitative narrative and a quantitative component that numerically describes the development of certain socioeconomic drivers of climate change (Arnell et al. 2011). The 'human core' of the SSPs consists of detailed population projections by age, sex, and level of education produced by the Wittgenstein Centre for Demography and Global Human Capital in Vienna (Lutz et al. 2014). The decision to include the education variable is based on the recognition that education plays an important role in both mitigation of and adaptation to future climate change (Lutz and Striessnig 2015). While the five different SSPs cannot depict all possible futures, they nevertheless span a broad range of scenarios that illustrate the main challenges associated with mitigation and adaptation, as described in detail by O'Neill et al. (2013).

In what is probably the most optimistic scenario, SSP1, the challenges in terms of both mitigation and adaptation are assumed to be small, and the world makes very substantial progress towards sustainability. This advancement is achieved by a high rate of technological progress and subsequent co-operation between the development leaders and followers. As a consequence, income levels rise steadily, poverty is further alleviated, and global inequality is reduced. On the demographic side, SSP1 corresponds to a rapid demographic transition driven by a rapid expansion of educational systems. Low levels of fertility in today's highfertility countries eventually lead to a comparatively low overall population levels.

SSP2 is referred to as the 'middle of the road' scenario because it assumes that the challenges associated with mitigation and adaptation to climate change will be at an intermediate level of severity. In this scenario, we experience the continuation of current trends with regard to development, democratisation, and shifts in the global energy mix towards more sustainable sources. Educational expansion occurs, but 
not as rapidly as in SSP1. In line with medium assumptions for both fertility and mortality, population growth does not decelerate to the same extent as in SSP1.

SSP3 describes a world of extreme fragmentation and polarisation. While some highly industrialised countries pull ahead, large fractions of the world population, particularly in the global south, are left behind, leading to staggeringly high levels of inequality across countries. The consequence of this trend is a stalled transition towards the establishment of knowledge-based societies. As education does not expand nearly as much as in the previous two scenarios, levels of fertility are high and population growth is unevenly distributed. Moreover, since international co-operation is reduced to a minimum, migration between the newly developing regional blocks of countries does not play a strong role in this scenario's population dynamics. Not surprisingly, the challenges associated with both mitigation and adaptation appear to be insurmountable in this scenario.

SSP4 is different from SSP3 mainly because in this scenario the challenges associated with mitigation are lower. Yet in SSP4, the adaptive capacities of societies are rather limited because of high levels of both within- and betweencountry inequality. On the one hand, large proportions of people do not make substantial contributions to global climate change, as they are simply not rich enough to adopt consumerist Western lifestyles. On the other hand, climate change becomes a particularly acute threat for the very large numbers of disadvantaged people who find it difficult to adapt. Demographically, this scenario corresponds to a high degree of inequality in the distribution of education. Fertility in the mediumincome developing countries is lower under SSP4 than under SSP3, while fertility in high-income countries is low under both SSP3 and SSP4. The recent increase in fertility in many rich low-fertility OECD countries (Myrskylä et al. 2009) is halted because the social transformations that facilitate this trend do not reach far enough.

Finally, SSP5 corresponds to conventional development: i.e. the idea that 'more of the same', or unrestricted economic growth, is going to solve all economic and social problems. While the environmental consequences of this emphasis on robust economic growth lead to major mitigation challenges, the adaptation challenges are rather small because of economic growth. Educational levels are assumed to be high throughout the world, but the fertility trends are more complex. While fertility is comparatively high in the countries that are currently rich and have low fertility, combining work and family becomes increasingly difficult everywhere else in the world. The overall effect on the world population is mixed.

Figure 2 shows the specific demographic implications of SSP1 to SSP5 in terms of total population by six major world regions. Although world population growth is driven primarily by developments in Asia and Africa, the SSPs also show very different pathways for the smaller regions. While SSP1 and SSP5 lead to rapid demographic transitions, and thus to lower overall population levels in the three regions at the bottom of the figure, the three more developed regions in the top part of the figure experience a reversal in their current fertility trajectories in these two scenarios. As population continues to increase in the more affluent parts of the world in particular, mitigation challenges for the planet as a whole are especially 
Figure 2:

Total population according to the five SSPs, six major world regions, 2010-2100
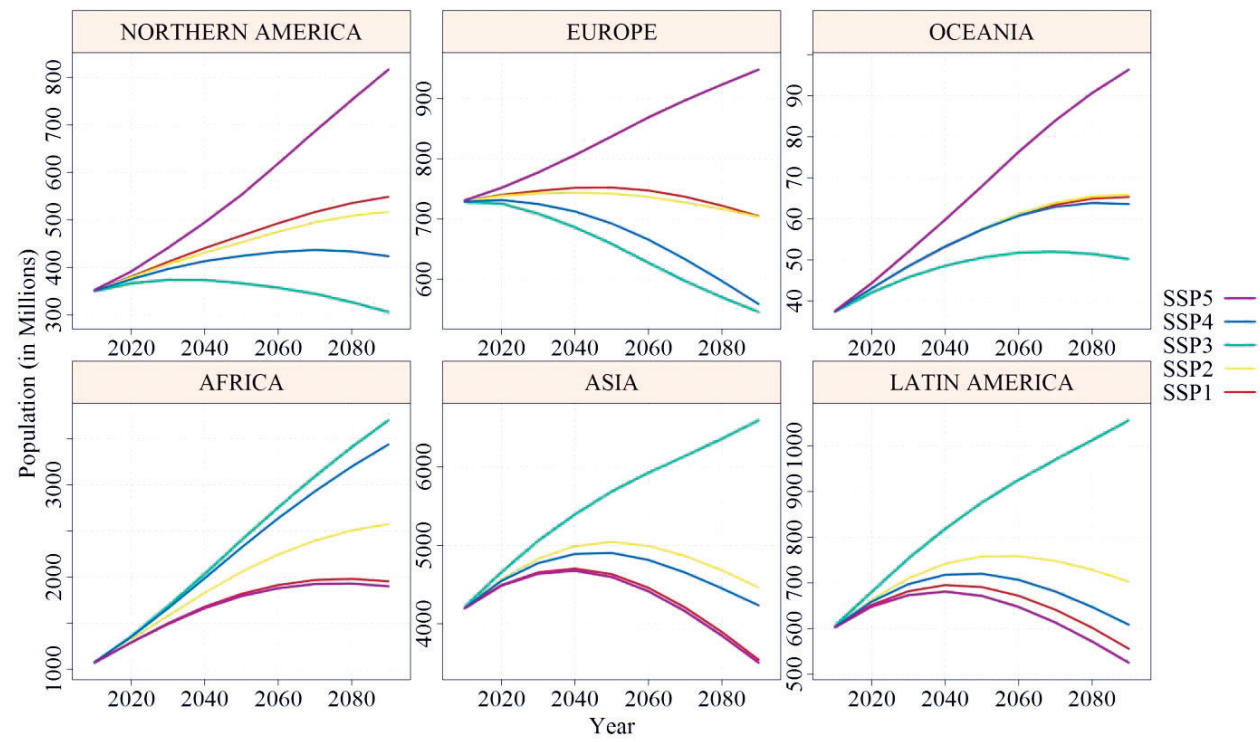

Figure 3:

Population by age, sex, and educational attainment according to the five SSPs, Africa, 2100

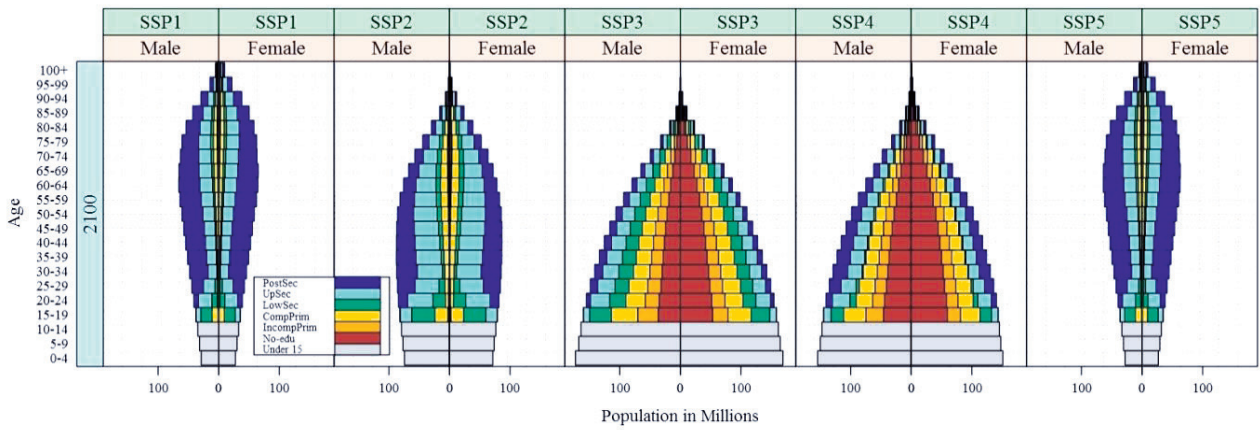

large under SSP5. The opposite effect can be observed in SSP3: while populations in the global north continue to age, fertility transitions in the south are stalled, and population reaches its maximum level across all of the five SSPs.

The SSPs differ not only in terms of overall population levels, but also in terms of the population distributions by age, sex, and educational attainment. This diversity 
of outcomes is illustrated by the case of Africa in 2100 in Figure 3. Interestingly, we can see that both SSP1 and SSP5 lead to very high levels of education and low levels of overall population. Yet the development pathways leading to these results are very different: in SSP1 the pathways are sustainability and low levels of emissions, while in SSP5 the pathways are conventional GDP-focused development and the highest emissions levels.

\section{Predicted disaster deaths under the SSPs}

We show the results for decadal projections of future disaster deaths in six major world regions (a complete list of the countries within each respective region can be found in Table A.1 in the appendix) by applying the regression estimates from Table 1 to the demographic scenarios underlying the SSPs. We assume unchanged hazard levels; i.e. we keep the number of disasters that enter the predictions constant. While these results are of course highly stylised, the primary focus of this exercise is to demonstrate the effects of different futures with regard to education, as well as population heterogeneity on the total number of deaths related to natural disasters. The trajectories presented in Figure 4 are shaped by both reduced vulnerability due to increases in educational attainment and increased vulnerability due to population growth. Since different sub-regions are projected to shift from having positive to having negative population growth in different decades, the regional aggregates of decadal deaths are not simply monotonic, but represent upward and downward trends. In addition, the SSPs do not contain explicit assumptions regarding the future hazard, future land use, or infant mortality. In our baseline calculations, we therefore assume that these indicators will remain at their respective values from the base period of our predictions throughout the entire $21^{\text {st }}$ century. The population growth rate and the share of women aged 20-39 with at least secondary education enter the projections with their respective country- and decade-specific values.

Figure 4 clearly shows that due to their sheer size relative to the other three regions, the bulk of disaster mortality in the $21^{\text {st }}$ century is expected to occur in Asia, Latin America and the Caribbean, and Africa. However, the ultimate trajectory depends on the specific population scenario. While under conditions of fragmentation (SSP3) all three regions experience strong increases in the number of deaths, under conditions of high levels of inequality (SSP4) Africa experiences worse effects than Asia and Latin America, as SSP4 is associated with significantly lower fertility levels than SSP3, and a smaller population is therefore at risk. In addition, inequality in the expansion of education is greater in SSP4 than in SSP3. Because the starting distributions of educational attainment are very different in the three regions, this trend has stronger effects in Asia and Latin America than in Africa. In the remaining scenarios casualty figures go down in all three regions.

However, our interpretation of these findings changes after we relate the projected number of deaths to the actual population in the respective SSP scenario (cf. Figure 2), as we do in Figure 5. We then see that the downward trend in the number 
Figure 4:

Predicted number of decadal deaths in 1000s, assuming constant hazard for six world regions, 2010-2100
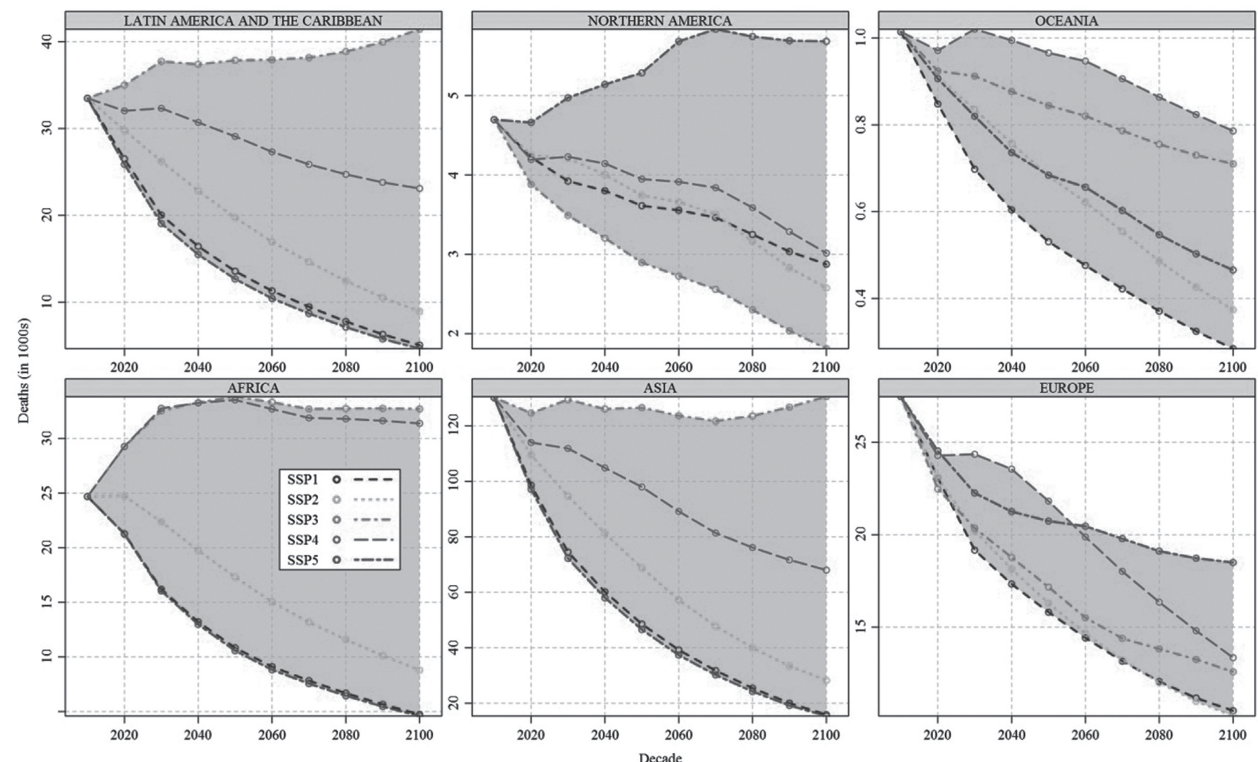

of deaths from extreme natural events experienced in the past will continue in all regions and SSPs, albeit at different levels. Another difference that becomes more pronounced when we look at deaths relative to total population size is that between Europe and North America. This gap is primarily attributable to the excess mortality associated with the 2003 summer heat wave, which according to EM-DAT figures caused roughly 20,000 deaths in Italy, 19,000 deaths in France, 15,000 deaths in Spain, and 9,000 deaths in Germany. In comparison, Hurricane Katrina, the largest individual disaster experienced by the US in the base period of our projections, caused 'only' 1,800 deaths. Based on these figures, the projected number of deaths is significantly larger in Europe.

\section{Discussion}

Our study has shown that different levels of investment in the educational attainment of populations around the world-captured in the individual definition of each SSP scenario-can result in dramatic differences in the predicted number of fatalities due to natural disasters related to climate change. The prediction of a decline in the number of decadal deaths in each of the six regions can be attributed to both higher 
Figure 5:

Predicted number of decadal deaths per million of population, assuming constant hazard for six world regions, 2010-2100

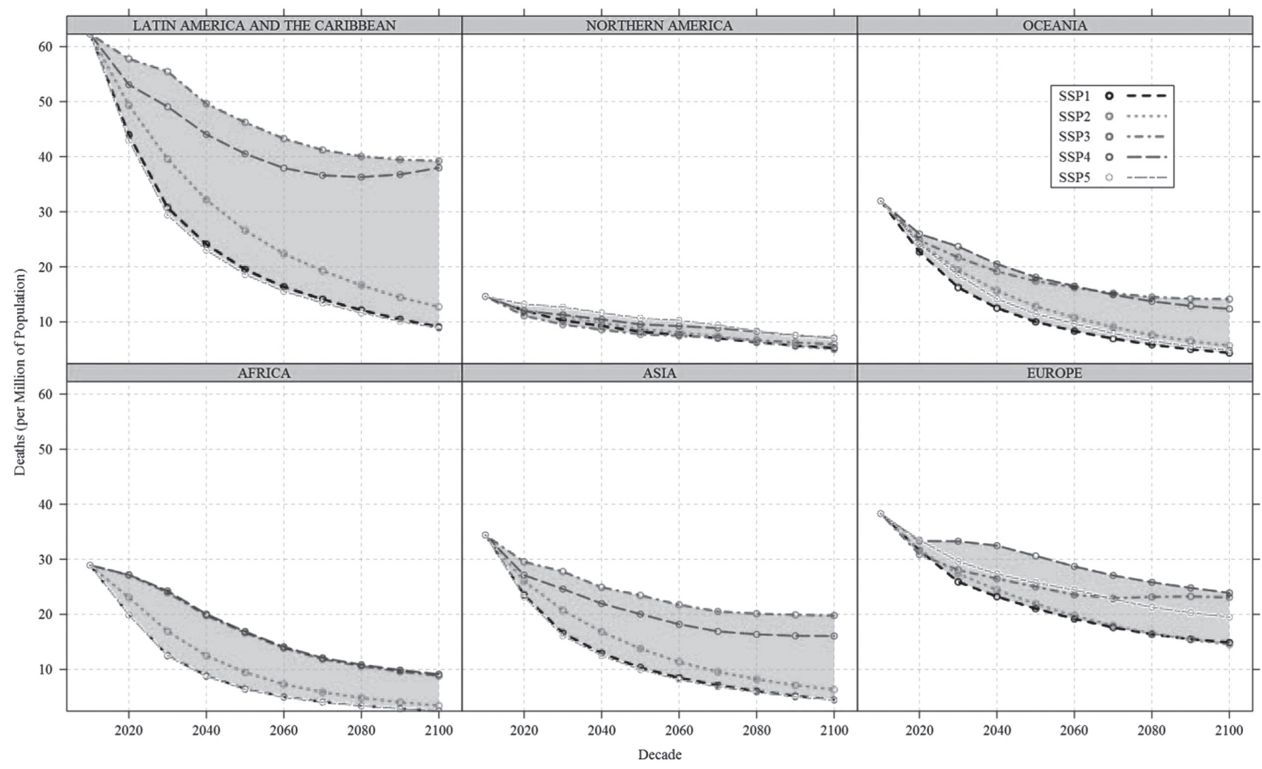

levels of education among populations and the accompanying effect of smaller populations at risk. Our analysis has shown these effects for the first time at the level of large world regions. Still, much more context-specific analysis of differential vulnerabilities and the role of demographic factors, including education, is needed in order to arrive at robust country-specific projections and policy recommendations. In general, however, our results support the claim that universal basic education of the entire population, including basic literacy and numeracy, is a key factor in enhancing the adaptive capacity and reducing the vulnerability of populations.

There are many uncertainties when examining the likely implications of the different SSPs on future disaster mortality, even without considering climate change. First, the demographic scenarios underlying the SSPs are not available in a probabilistic format. Thus, we are not able to assign probabilities to specific prediction outcomes. Instead, the SSPs are intended to span a reasonable range of possible futures, and our primary goal here was to translate this range in terms of future numbers of disaster deaths to complement assessments of the future vulnerability of people in different parts of the world.

Another uncertainty is related to the extent to which climate change is going to affect the number of extreme events in those different scenarios. As there is to date no comparable translation of the SSPs into future numbers of natural disasters for different geographic areas, we are forced to make some rather general assumptions 
about the frequency of all types of hydro-meteorological extreme events. Hence, we are unable - as Kriegler et al. (2012) put it — to 'close the loop', and to study how climate outcomes respond to differences in the SSPs. Certainly, low radiative forcing levels will be harder to achieve at very high population levels (i.e. SSP3 and SSP4), and attempts to mitigate the consequences of climate change, which are more likely to succeed under conditions of sustainable development than under conditions of conventional development, will affect the challenges associated with adaptation.

Another point to keep in mind is the possibility of a spatial redistribution of populations as an adaptation strategy, which is not considered in our model. In addition, due to emergency preparedness plans that have been implemented in response to previous natural disasters (for example, many European cities implemented such plans in reaction to the high number of excess deaths during the 2003 heat wave, and these plans appear to have greatly reduced casualty numbers during subsequent heat waves; see Cadot et al. 2007), it is less likely that similar events will lead to similar numbers of casualties in the future. Studying these extremely important dynamics is left to future analyses.

Since the general assumption behind the results shown is that hazard levels will remain constant at base period levels, the finding that casualty figures are almost universally going down is of course somewhat optimistic. Indeed, most climate scientists would view this as a rather unlikely scenario. Since the assessment of the future frequency of natural disasters around the world depends on a myriad of factors, such as geography and societies' capacities to prevent extreme natural events from turning into disasters, the IPCC is rather careful in quantifying the effect of climate change on the number of extreme natural events. There seems to be a general consensus, however, that almost all types of disasters are becoming more frequent as a consequence of sea level rise and higher global mean temperatures (IPCC 2014). Hence, the projected numbers of deaths are conservative, and are thus probably too low.

\section{Acknowledgements}

Funding for this work was made possible by an Advanced Grant of the European Research Council 'Forecasting Societies Adaptive Capacities to Climate Change': grant agreement ERC-2008-AdG 230195-FutureSoc and the 'Wittgenstein Award' of the Austrian Science Fund (FWF): Z171-G11.

\section{References}

Arnell, N., T. Kram, T. Carter, K. Ebi, J. Edmonds, S. Hallegatte, E. Kriegler, et al. 2011. A framework for a new generation of socioeconomic scenarios for climate change impact, adaptation, vulnerability and mitigation research. Scenario Framework Paper. Potsdam Institute for Climate Impact Research. 
Atkins, D. C., S. A. Baldwin, C. Zheng, R. J. Gallop and C. Neighbors 2013. A tutorial on count regression and zero-altered count models for longitudinal substance use data. Psychology of Addictive Behaviors 27(1): 166-77.

Brooks, N., W. N. Adger and P. M. Kelly 2005. The determinants of vulnerability and adaptive capacity at the national level and the implications for adaptation. Global Environmental Change Part A 15(2): 151-63.

Butz, W. P., W. Lutz and J. Sendzimir (eds) 2014. Education and differential vulnerability to natural disasters. Ecology $\mathcal{F}$ Society, Special Feature.

Cadot, E., V. G. Rodwin and A. Spira 2007. In the heat of the summer. Journal of Urban Health: Bulletin of the New York Academy of Medicine 84(4): 466-68.

Crespo Cuaresma, J. 2015. Income projections for climate change research: A framework based on human capital dynamics. Global Environmental Change, in press. doi:10.1016/j.gloenvcha.2015.02.012.

EM-DAT, CRED 2010. The OFDA/CRED International Disaster Database. Brussels: Université Catholique de Louvain, Center for Research on the Epidemiology of Disasters (CRED). http://www.em-dat.net.

Frome, E. L., J. P. Watkins, E. D. Ellis and C. H. Strader 2012. Poisson regression analysis of illness and injury surveillance data. Oak Ridge Institute for Science and Education (ORISE), Oak Ridge, TN (United States).

Hegre, H., H. Buhaug, K. V. Calvin, J. Nordkvelle, S. T. Waldhoff and E. Gilmore 2016. Forecasting civil conflict along the shared socioeconomic pathways. Environmental Research Letters 11(5), 54002.

Heston, A., R. Summers and B. Aten 2012. Penn World Table Version 7.1. Center for International Comparisons of Production, Income and Prices at the University of Pennsylvania.

Hinkel, J., D. Lincke, A. T. Vafeidis, M. Perrette, R. J. Nicholls, R. S. J. Tol, B. Marzeion, X. Fettweis, C. Ionescu and A. Levermann 2014. Coastal flood damage and adaptation costs under 21st century sea-level rise. Proceedings of the National Academy of Sciences 111(9): 3292-97.

Hunter, L. M. and B. C. O'Neill 2014. Enhancing engagement between the population, environment, and climate research communities: The shared socio-economic pathway process. Population and Environment 35(3): 231-42.

IPCC 2014. Climate Change 2014: Synthesis Report. Contribution of Working Groups I, II and III to the Fifth Assessment Report of the Intergovernmental Panel on Climate Change. IPCC Fifth Assessment Synthesis Report. Geneva, Switzerland: Intergovernmental Panel on Climate Change.

Jiang, L. and B. C. O'Neill 2015. Global urbanization projections for the Shared Socioeconomic Pathways. Global Environmental Change, in press. doi:10.1016/j.gloenvcha.2015.03.008.

KC, S. and W. Lutz 2014. Demographic scenarios by age, sex and education corresponding to the SSP narratives. Population and Environment 35(3): 243-60.

KC, S., W. Lutz, E. Loichinger, R. Muttarak and E. Striessnig 2014. Reducing vulnerability in critical life course phases through enhancing human capital. Interim Report IR-14-001. Laxenburg, Austria: Institute for Applied Systems Analysis. 
KC, S., M. Potančoková, R. Bauer, A. Goujon and E. Striessnig 2014. Data and methods. In World population and human capital in the 21 st century, eds W. Lutz, W. P. Butz and S. KC, 434-518. Oxford: Oxford University Press.

Kriegler, E., B. C. O'Neill, S. Hallegatte, T. Kram, R. J. Lempert, R. H. Moss and T. Wilbanks 2012. The need for and use of socio-economic scenarios for climate change analysis: A new approach based on shared socio-economic pathways. Global Environmental Change 22(4): 807-22.

Lutz, W., W. P. Butz and S. KC (eds) 2014. World population and human capital in the 21 st century. Oxford, UK: Oxford University Press.

Lutz, W., J. Crespo Cuaresma and M. J. Abbasi-Shavazi 2010. Demography, education, and democracy: Global trends and the case of Iran. Population and Development Review 36(2): 253-81.

Lutz, W., J. Crespo Cuaresma and W. C. Sanderson 2008. The demography of educational attainment and economic growth. Science 319(5866): 1047-48.

Lutz, W. and E. Striessnig 2015. Demographic aspects of climate change mitigation and adaptation. Population Studies 69: S69-76.

Marshall, M. G. and K. Jaggers 2005. Polity IV Project: Political regime characteristics and transition, 1800-2004. www.cidcm.umd.edu/inscr/polity.

Muttarak, R. and W. Lutz 2014. Is education a key to reducing vulnerability to natural disasters and hence unavoidable climate change? Ecology $\mathcal{E}$ Society, Education and Differential Vulnerability to Natural Disasters, 19(1): 42.

Myrskylä, M., H.-P. Kohler and F. C. Billari 2009. Advances in development reverse fertility declines. Nature 460(7256): 741-43.

O’Neill, B. C., E. Kriegler, K. Riahi, K. L. Ebi, S. Hallegatte, T. R. Carter, R. Mathur and D. P. van Vuuren 2013. A new scenario framework for climate change research: The concept of shared socioeconomic pathways. Climatic Change 122(3): 387-400.

Pamuk, E. R., R. Fuchs and W. Lutz 2011. Comparing relative effects of education and economic resources on infant mortality in developing countries. Population and Development Review 37(4): 637-64.

Striessnig, E., W. Lutz and A. G. Patt 2013. Effects of educational attainment on climate risk vulnerability. Ecology $\mathcal{E}$ Society 18(1): 16.

United Nations 2013. World Population Prospects: The 2012 Revision. Key Findings and Advance Tables. New York, NY: Department of Economic and Social Affairs, Population Division. http://esa.un.org/unpd/wpp/Documentation/publications.htm.

van Vuuren, D. P., K. Riahi, R. Moss, J. Edmonds, A. Thomson, N. Nakicenovic, T. Kram, F. Berkhout, R. Swart and A. Janetos 2012. A proposal for a new scenario framework to support research and assessment in different climate research communities. Global Environmental Change 22(1): 21-35.

World Bank 2012. 2012 World Development Indicators Online. Washington, DC: The World Bank. http://data.worldbank.org/indicator/AG.LND.ARBL.ZS.

Zagheni, E., R. Muttarak and E. Striessnig (2015). The impact of climate change on the demography of meteorological disaster mortality. Vienna Yearbook of Population Research 13: 47-70. 
Zeileis, A., C. Kleiber and S. Jackman 2007. Regression models for count data in R. https://cran.r-project.org/web/packages/pscl/vignettes/countreg.pdf.

\section{Appendix}

Table A.1:

\section{Countries by world region}

\begin{tabular}{|c|c|c|c|c|c|}
\hline Asia & Europe & Africa & $\begin{array}{l}\text { Latin America and } \\
\text { The Caribbean }\end{array}$ & Oceania & $\begin{array}{l}\text { Northern } \\
\text { America }\end{array}$ \\
\hline Afghanistan & Albania & Algeria & Argentina & Australia & Canada \\
\hline Armenia & Austria & Angola & Bahamas & Fiji & $\begin{array}{l}\text { United States of } \\
\text { America }\end{array}$ \\
\hline Azerbaijan & Belarus & Benin & Barbados & French Polynesia & \\
\hline Bangladesh & Belgium & Botswana & Belize & Guam & \\
\hline Bhutan & $\begin{array}{l}\text { Bosnia and } \\
\text { Herzegovina }\end{array}$ & Burkina Faso & Bolivia & $\begin{array}{l}\text { Micronesia (Fed. } \\
\text { States of) }\end{array}$ & \\
\hline Brunei Darussalam & Bulgaria & Burundi & Brazil & New Caledonia & \\
\hline Cambodia & Croatia & Cameroon & Chile & New Zealand & \\
\hline China & Czech Republic & Cape Verde & Colombia & Papua New Guinea & \\
\hline Cyprus & Denmark & $\begin{array}{l}\text { Central African } \\
\text { Republic }\end{array}$ & Costa Rica & Samoa & \\
\hline $\begin{array}{l}\text { Dem. People's } \\
\text { Republic of Korea }\end{array}$ & Estonia & Chad & Cuba & Solomon Islands & \\
\hline Georgia & Finland & Comoros & Dominican Republic & Tonga & \\
\hline India & France & Congo & Ecuador & Vanuatu & \\
\hline Indonesia & Germany & Cote d'Ivoire & El Salvador & & \\
\hline $\begin{array}{l}\text { Iran (Islamic } \\
\text { Republic of) }\end{array}$ & Greece & $\begin{array}{l}\text { Democratic } \\
\text { Republic of } \\
\text { the Congo }\end{array}$ & Grenada & & \\
\hline Iraq & Hungary & Djibouti & Guatemala & & \\
\hline Israel & Iceland & Egypt & Guyana & & \\
\hline Japan & Ireland & Eritrea & Haiti & & \\
\hline Jordan & Italy & Ethiopia & Honduras & & \\
\hline Kazakhstan & Latvia & Gabon & Jamaica & & \\
\hline Kuwait & Lithuania & Gambia & Mexico & & \\
\hline Kyrgyzstan & Luxembourg & Ghana & Nicaragua & & \\
\hline $\begin{array}{l}\text { Lao People's } \\
\text { Democratic } \\
\text { Republic }\end{array}$ & Netherlands & Guinea & Panama & & \\
\hline Lebanon & Norway & Guinea Bissau & Paraguay & & \\
\hline Malaysia & Poland & Kenya & Peru & & \\
\hline Maldives & Portugal & Lesotho & Puerto Rico & & \\
\hline Mongolia & Republic of Moldova & Liberia & Saint Lucia & & \\
\hline Myanmar & Romania & $\begin{array}{r}\text { Libyan Arab } \\
\text { Jamahiriya }\end{array}$ & $\begin{array}{c}\text { Saint Vincent and } \\
\text { the Grenadines }\end{array}$ & & \\
\hline Nepal & Russian Federation & Madagascar & Suriname & & \\
\hline Oman & Slovakia & Malawi & Trinidad and Tobago & & \\
\hline Pakistan & Slovenia & Mali & Uruguay & & \\
\hline Philippines & Spain & Mauritania & $\begin{array}{l}\text { Venezuela } \\
\quad \text { (Bolivarian } \\
\text { Republic of) }\end{array}$ & & \\
\hline
\end{tabular}

\section{Continued}


Table A.1:

Continued

\begin{tabular}{|c|c|c|c|c|c|}
\hline Asia & Europe & Africa & $\begin{array}{l}\text { Latin America and } \\
\text { The Caribbean }\end{array}$ & Oceania & $\begin{array}{l}\text { Northern } \\
\text { America }\end{array}$ \\
\hline Republic of Korea & Sweden & Mauritius & & & \\
\hline Saudi Arabia & Switzerland & Morocco & & & \\
\hline Sri Lanka & TFYR Macedonia & Mozambique & & & \\
\hline $\begin{array}{l}\text { Syrian Arab } \\
\text { Republic }\end{array}$ & Ukraine & Namibia & & & \\
\hline Tajikistan & United Kingdom & Niger & & & \\
\hline Thailand & & Nigeria & & & \\
\hline Timor Teste & & Rwanda & & & \\
\hline Turkey & & $\begin{array}{l}\text { Sao Tome and } \\
\text { Principe }\end{array}$ & & & \\
\hline Uzbekistan & & Senegal & & & \\
\hline Viet Nam & & Sierra Leone & & & \\
\hline \multirow[t]{11}{*}{ Yemen } & & Somalia & & & \\
\hline & & South Africa & & & \\
\hline & & Sudan & & & \\
\hline & & Swaziland & & & \\
\hline & & Togo & & & \\
\hline & & Tunisia & & & \\
\hline & & Uganda & & & \\
\hline & & United Republic of & & & \\
\hline & & Tanzania & & & \\
\hline & & Zambia & & & \\
\hline & & Zimbabwe & & & \\
\hline
\end{tabular}




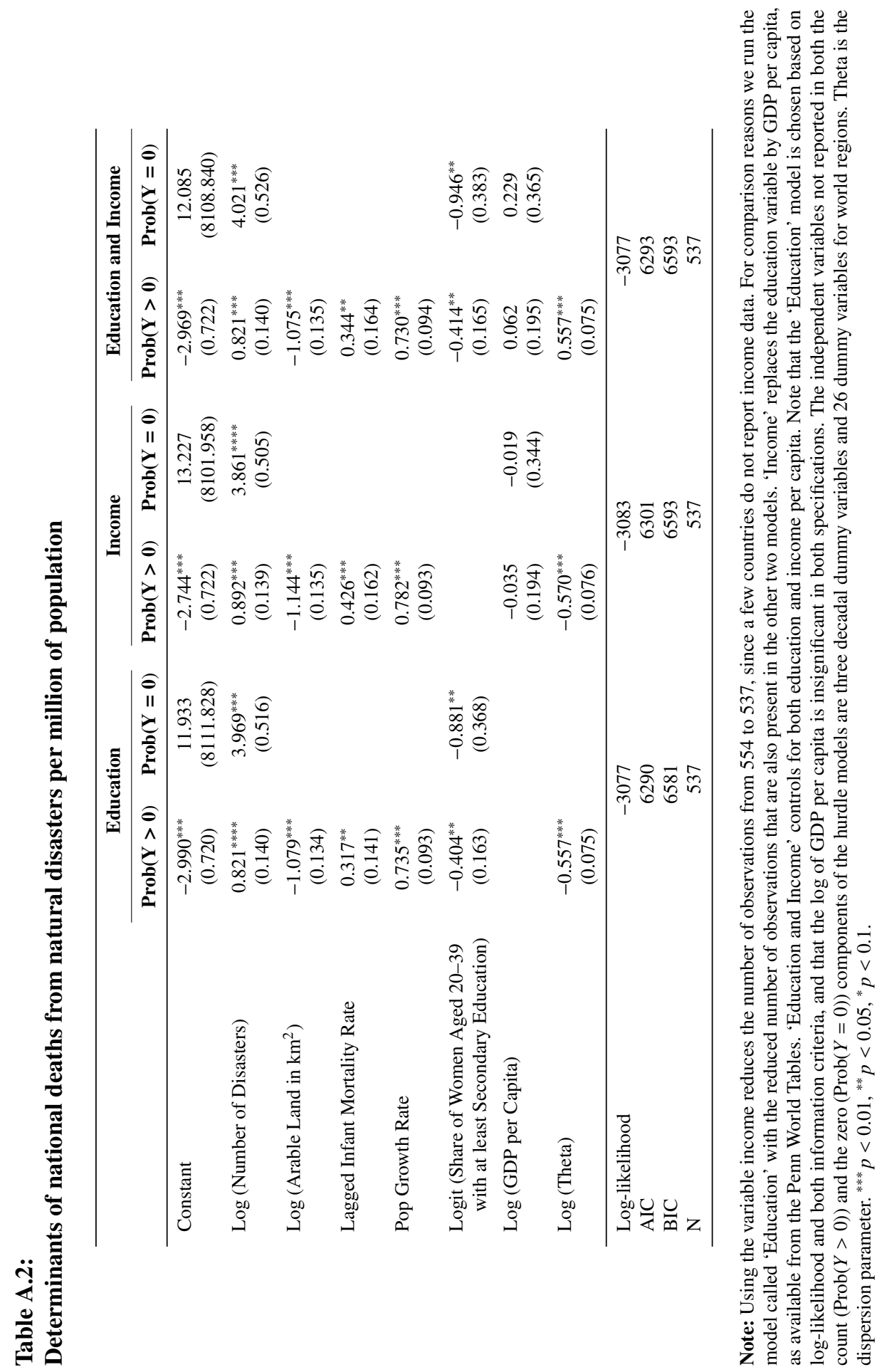




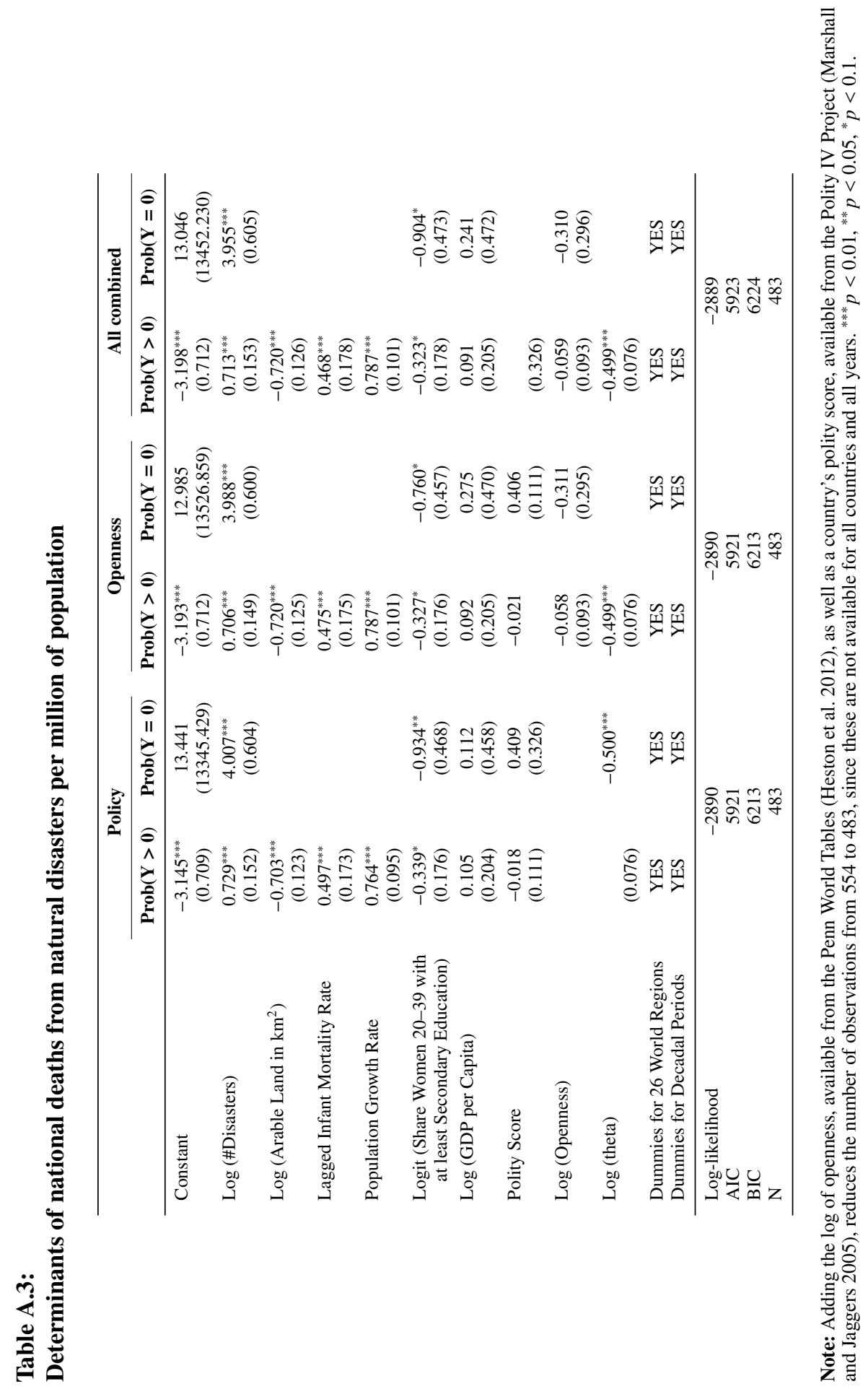

